\title{
Pecan and Walnut Food Safety Concerns: A Mini Review
}

\author{
Conner McDaniel ${ }^{1}$, Ravi Jadeja ${ }^{1,2 *}$ \\ ${ }^{1}$ Department of Animal \& Food Sciences, Oklahoma State University, Stillwater, OK, 74078, USA \\ ${ }^{2}$ Robert M. Kerr Food \& Ag Product Center, Oklahoma State University, Stillwater, OK, 74078, USA
}

Received Date: June 18, 2021; Accepted Date: June 22, 2021; Published Date: July 01, 2021

"Corresponding author: Ravi Jadeja, Associate Professor \& Food Safety Specialist, 106 FAPC, Oklahoma State University, Stillwater, Oklahoma, 74078, USA. Tel: +14057443922; Email: ravi.jadeja@okstate.edu

\section{Abstract}

Consumption of tree nuts in the U.S. and worldwide is growing rapidly due to the health benefits associated with the nuts. Unfortunately, tree nuts are also notoriously associated with numerous foodborne illness outbreaks and recalls. This review focuses on food safety concerns related to growing, harvesting, and shelling pecans and walnuts in the U.S. The review provides a brief overview of pecan and walnut production and processing practices in the U.S. The review also details common routes of foodborne pathogen contamination of tree nuts and the risk reduction strategies utilized by the nut industry. The role of Good Agricultural Practices, Hazard Analysis and Critical Control Plan, and Food Safety Modernization Act in improving the overall microbial safety of pecans and walnuts are also discussed in the article.

Keywords: E. coli O157:H7; Food Safety; FSMA; L. monocytogenes; Pecan; Salmonella spp; Sanitizers; Walnut

Pecan and Walnut Consumption, Health Benefits, Harvest and Production Practices

The quantity of tree nuts consumed in the United States has grown steadily in the past 20 years. For comparison, in 2000, the per capita consumption of tree nuts in the U.S. was 2.61 pounds, while in $2018,5.1$ pounds of tree nuts were consumed [1]. Nuts in general tend to be good sources of fat, fiber, and protein and in addition contain many vitamins and minerals. For these reasons and more, nuts are considered and often recommended by health officials around the world as an important component of a healthy diet [2]. Pecans (Caryaillinoinensis) and walnuts (Juglans sp.) are both members of the Juglandaceae family along with hickory (Carya) [3-5].

\section{Pecans}

Pecan trees are native to North America, specifically northern Mexico and the southern United States [6]. Wild growing pecan trees were well known and utilized by native Americans, however, commercial growing of pecans in the United States did not take place until the 1800s [7]. Pecan trees have many economic uses including charcoal, fuel wood, nut production, and wood [8-10]. The United States is the world's leading pecan producer ( $80 \%$ of global production), and Georgia is the leading state in production accounting for $33 \%$ of U.S. pecan harvest (approx. 100 million pounds inshell) followed by New Mexico with $26 \%$ of U.S. harvest (approximately 72 million pounds in-shell), and Texas is the third highest producer of pecans in the U.S. with approximately 37 million pounds of in-shell pecans harvested [11,12]. In 2019, the United States pecan production totalled 265 million pounds and the crop profited \$469 million according to the National Agricultural Statistics Service (N.A.S.S.). Native pecan groves are prevalent along valleys of rivers and streams in Louisiana, Oklahoma, and Texas [4].

Pecans are typically harvested between October and December every year. During shuck split, pecan hulls begin to dehisce meaning the green hull opens while on the tree, indicating to harvesters that the pecans are ready to be harvested. Pecan harvesters use hydraulic shakers to speed the 
process of nuts falling to the ground. Once on the ground, the nuts are swept and then picked up by a mechanical harvester. The pecans are then transported to a hulling facility where the hulls and nuts are separated. Following hulling, the pecans are dried to a moisture content at or below $4.5 \%$ [13]. Pecans can be sold in shell or can be further processed. Common processing techniques include, cracking, chopping, candying, or pecans can be used as an ingredient in other food products. The consumption of pecans is widespread in North America where consumers enjoy them most commonly as a snack or dessert ingredient, such as in praline candy and pecan pie [3].

Pecans provide many nutritional benefits to human consumers and can be a part of a healthy diet. The consumption of one ounce of pecans provides $10 \%$ of the daily fiber intake that is recommended for adults. Pecans are rich in fats, approximately 58.1-66.18g oil in $100 \mathrm{~g}$ nuts [14,15]. This high fat content could potentially lead to many consumers avoiding the consumption of pecan nuts; however, evidence shows that the inclusion of foods into the diet that are rich in appropriate, naturally occurring fats is critical in the promotion of a healthy lifestyle and a reduced risk of obesity, which can lead to secondary conditions such as hyperglycemia and hypertension [3]. Furthermore, the consumption of pecan nuts has been found to have an association with improved blood lipid profiles, lower cholesterol levels and reduced risk of developing cardiovascular disease [16-18].

Pecans are also a source of phenolic compounds or polyphenols. In fact, pecan nuts have been reported as having the highest total polyphenol content when compared against 10 diverse types of nuts, specifically, almonds, Brazil nuts, cashews, hazelnuts, macadamias, peanuts, pine nuts, pistachios and walnuts [19]. Polyphenol compounds are naturally occurring antioxidants produced as a result of the secondary metabolism of plants and are present in abundance within plant food products [20-23]. These compounds are a known contributor to plant defense and support strategies, with involvement in pathogen and predator resistance, serving as attractants or feeding deterrents, stress protection, plant crop security from plague, prevention of preharvestseed germination and contribution to growth and reproduction of plants [20, 22, 24]. Industrial applications of polyphenols within the food industry include food additives such as natural food coloring agents and food preservatives $[\mathbf{2 5}, \mathbf{2 6}]$.

In addition to the benefits phenolic compounds provide to plants and their industrial applications, some phenolic compounds such as flavonoids, have applications in the improvement of human health [24]. Polyphenols constitute the highest antioxidants in the human diet likely due to their wide distribution in plants and therefore plant food products [27]. It is believed that phenolic compounds are beneficial to human health due to their antioxidant, anti-aging, antibacterial, anti-cancer, antiinflammatory, antimutagenic and antiviral properties [28-37].

\section{Walnuts}

Walnuts are globally popular and valued for their nutritional, sensory and health attributes [38]. Their consumption dates to 7,000 B.C. and in these ancient times, walnuts were known and consumed for both their medicinal uses as well as their health benefits. Walnuts have several economic uses including shade, shelter, walnuts, wood, and the utilization of walnut husks to produce dyes $[8,39-41]$. Walnuts comprise the sixth most valuable fruit and tree nut crop in the United States [42, 43]. The production of walnuts in China and the United States combined, accounts for more than $75 \%$ of the global output [44]. California is responsible for the production of $99 \%$ of the walnuts produced in the United States and produces approximately 1 billion pounds of walnuts every year [45].

Walnuts are harvested in the fall (late August- November) every year [46]. Walnuts have outer green hulls that begin to dry and split, signifying that they are ready to be harvested. By the time harvest begins, there are typically a small number of walnuts that have naturally fallen to the ground. A mechanical shaker which grabs the tree by the trunk is utilized to remove walnuts from the tree by vigorous shaking. The walnuts are shaken to the ground where they are then swept and picked up by a mechanical harvest machine [47]. Care is taken to reduce the amount of time the nuts spend on the ground, to minimize the potential of pathogen contamination by soil contact. The walnuts are then transported to a huller which uses scrubbers to remove green hulls [48]. The nuts are then dried to reach approximately $8 \%$ moisture level prior to being stored or processed [49]. Drying the nuts helps to prevent quality loss of the nut during storage. After drying, walnuts can be stored for up to a year and are sold as either in-shell nuts or packaged as walnut halves or pieces [48]. The seed or kernel of the walnut is consumed, either raw or toasted. Often, walnuts are added to other food products as an ingredient or topping.

Walnuts are considered nutrient-dense because of their protein, vitamin, and fat content. Additionally, walnuts are a good source of phenolic compounds, which are described in detail in section 1.1. Walnuts possess a high content of $\alpha$ Linolenic Acid (A.L.A.), a vegetable n-3 fatty acid, which separates them nutritionally from other nut varieties $[\mathbf{5 0}, \mathbf{5 1}]$. It has been reported that the regular consumption of walnuts can lower total plasma and low-density lipoprotein (LDL) cholesterol [52]. Additionally, a positive effect on blood HighDensity Lipoprotein (HDL) cholesterol and apolipoprotein A1 from the consumption of walnuts has-been reported [53]. Walnut consumption also provides heart health benefits by reducing inflammation and improving arterial function [51, 54, 55]. There have been studies which suggest that the consumption of walnuts can aid in the maintenance of brain health with age [56].

\section{2 | Advances in Nutrition and Food science, Volume 2021, Issue 03}


Food borne Pathogen Contamination and Pathogens of Concern for Pecans and Walnuts

Consumers utilize tree nuts as an ingredient in many ways, some of which involve cooking or other thermal treatment and others do not. Non thermal uses of nuts include, consuming raw nuts or adding nuts to cereals or salads. In these cases, there has been no method performed by the consumer to reduce potential pathogen contamination. Heat serves as an effective bacterial pathogen mitigation step, but the effectiveness is based largely on the temperature and time of exposure to the temperature. Most consumer at-home nut processing treatments are not sufficient to inactivate pathogens, however, the heating process that occurs in the creation of brittle or toffee $\left(350^{\circ} \mathrm{F} / 177^{\circ} \mathrm{C}\right.$ or higher) could potentially inactivate pathogens which may be present [57]. Therefore, it is important to ensure that consumers are receiving nuts free of pathogens since many uses of nuts do not include effective pathogen inactivation steps. Consequently, understanding the routes of possible nut contamination, the pathogens commonly associated with nuts, and the implementation and improvement of processes to reduce possible contamination is of upmost importance.

\section{Pecan and Walnut Foodborne Pathogen Contamination}

It has been assumed that intact shells on nuts protect the product from any microbial contamination [58-60]. However, it has been reported that pathogen contamination of nuts can occur even when shells appear to be completely intact [60-63]. Furthermore, shells surrounding nuts are prone to breakage during harvest and postharvest processing, which can expose the edible nut and increase the potential for pathogen contamination $[60,62,64]$. Contamination of tree nuts by foodborne pathogens can occur as early as on the orchard. This can be caused by the application of sprays made with contaminated water, animal invasion, and direct contact with contaminated soil, human handling, and contaminated harvest equipment or during storage [49]. Pecans and walnuts are shaken to the ground during harvest, which can be problematic in regards to product contamination as the floor of the orchard is considered to be a potential source of pathogen contamination [65]. Pathogen contamination originating on the orchard can be spread to the edible nut meats during further processing [66]. During post-harvest processing of pecans and walnuts, the nuts are typically introduced to a float tank which does not usually include antimicrobial agents and is high in organic matter [67]. This water is susceptible to contamination and can thereby cause cross-contamination among further batches of processed nuts. In fact, one study found that E. coli contaminated water sampled during black walnut hulling, directly correlated with a sample of highly contaminated nuts [60].

\section{Pathogens of Concern for Pecans and Walnuts}

\section{Salmonella}

Salmonella spp. is a gram-negative, facultative anaerobe. Six subspecies consisting of more than 2,700 serotypes compose Salmonella and all are presumed to be pathogenic. This bacterium has peritrichous flagella which provide motility and is a member of the Enterobacteriaceae family [68]. Salmonella possess the ability to form biofilms; which are groups of bacteria protected by an extracellular polymeric substances (EPS) matrix that adhere to surfaces and are difficult to remove or kill $[6 \mathbf{6 9 , 7 0 ]}$. Non-typhoidal Salmonella has been estimated to cause one million food borne illnesses and approximately 130 outbreaks annually in the United States [71]. The C.D.C. notes that in general, within 12-72 hours individuals who are infected with Salmonella will show symptoms of diarrhea, fever and abdominal cramps [72]. The illness caused by infection with Salmonella is often referred to as Salmonellosis. Salmonellosis can last from four to seven days, and although treatment is typically not required, diarrhea caused by this infection can become severe enough to require hospitalization. Individuals who are immune compromised, children and the elderly are among the most vulnerable to this pathogen [73].

Nuts have a water activity below 0.7 , which leads many to believe they are an unlikely source of Salmonella contamination [73]. Most commonly, Salmonella is associated with animal and animal products. However, it has been proven that Salmonella is capable of surviving for several months in low-moisture food products kept at refrigerated or room temperature [57, 74-76]. Further, outbreaks associated with this pathogen have proven that although Salmonella is unable to grow in low-moisture food products, it is able to survive in numbers sufficient enough to cause human illness [74, 75]. Salmonella infection has been documented as occurring from the consumption of low-moisture food products with contamination less than $1 \mathrm{CFU} / \mathrm{g}$ [77], however, this is dependent on the consumer, type of food product and the specific strain involved.

Many consumers believe that storing nuts in the refrigerator or freezer will eliminate the threat of bacterial pathogens, however, in the case of Salmonella, survival time of the pathogen is increased as storage temperature is decreased [78]. In fact, Salmonella on raw almonds did not decrease over 1.5 years of refrigerated or frozen storage [78]. Additionally, because nuts possess a high amount of monounsaturated and polyunsaturated fats [79], storage at room temperature for an extended amount of time, can result in rancidity. This is because the stability of unsaturated fats depends on temperature and increased temperatures result in a shorter shelf life of the food product. Therefore, although the survival time of Salmonella on nuts is increased when exposed to 
cooler temperatures, refrigerator or freezer storage is necessary to prolong their shelf life [80].

Salmonella, is a pathogen that is typically heat-resistant especially when the contamination is in food products that are low-moisture [81]. Another factor to consider is the complexity of the food matrix that nuts are added to prior to being baked or otherwise heated. Some of the most common food products that nuts are added to include cookies, breads, candies, cakes or muffins, all of which often include high fat and sugar contents. The thermal inactivation of Salmonella can be influenced by the fat level, $\mathrm{pH}$, water activity and salt content of the food matrix it is contaminating [82, 83]. It is thought that a high fat content protects Salmonella from acids present in the stomach [84], and high sugar content lowers water activity and also provides some protection to Salmonella [85].

In 2004 raw almonds were linked to an outbreak of Salmonellosis illness [86]. In 2009, shelled roasted hazelnuts were recalled following testing positive for Salmonella [87]. Additionally, pistachios and pecans were recalled in 2009 following the isolation of Salmonella during routine product testing [88, 89]. In 2015, at least 25 recalls were issued as a result of Salmonella contamination of almonds, hazelnuts, macadamia nuts, pecans and pine nuts [90].

\section{Escherichia coli}

E. coli belongs to the family Enterobacteriaceae, has many different strains and is a gram-negative rod-shaped bacterium. Some strains of this bacterium are non-pathogenic and occur naturally in the gastrointestinal tracts of humans. However, some strains, namely those which naturally occur in ruminant animals such as cattle, can be shed through animal feces and cause human food contamination and illness. Shiga toxigenic E. coli (STEC) are important to food safety because of their impact on human health. These strains have the ability to produce and release toxins in human hosts. These toxins can impose illness and even death in humans.

Within STECs, a group known as "the big six" has been prominent in outbreaks over the past two decades. These strains include E. coli 026, O45, O103, O111, O121, and O145. The big six along with $E$. coli $\mathrm{O} 157: \mathrm{H} 7$ are listed by the United States Department of Agriculture (USDA.) as zero tolerance pathogens, meaning no single cells of these strains can be detected in food products without a recall or other intervention imposed. This strict requirement is likely influenced by the low infectious dose that is seen with $E$. coli. In fact, only approximately 100 cells of these pathogens are required to be ingested to cause illness in humans [91]. Estimations suggest that STECs are responsible for over 112,000 foodborne illnesses every year, resulting in more than 27 million dollars in medical expenses [92].
The symptoms experienced by an individual who has an STEC infection can include abdominal pain or cramping, diarrhea, and bloody diarrhea. However, more serious cases can lead to the infected individual developing hemolyticuremic syndrome (H.U.S.) or hemorrhagic colitis. More serious cases typically present in individuals who are immune compromised [93, 93]. Complications from any of the symptoms imposed by STEC infection have the potential to result in death.

The contamination of tree nuts with E. coli can occur in many ways. Contaminated animal feces can further contaminate soil and water [95]. If appropriate preventative steps are not in place by the producer, contaminated irrigation water can introduce the pathogen to unharvested nuts. Additionally, some nuts fall prior to harvest and as a result encounter the soil for an extended amount of time. If $E$. coli is present in the soil, the pathogen can contaminate the nut product. Finally, human contact or equipment contact during harvest can result in product contamination if the pathogen is present. E. coli O157:H7 has been linked to contamination of peanuts, pecans, and walnuts [96-98].

\section{Listeria monocytogenes}

Listeria monocytogenes (L. monocytogenes) is a foodborne pathogen that is of major concern in the United States [99]. This pathogen is a Gram-positive, non-spore-forming, rod [100], as well as a facultative anaerobe meaning its survival is not dependent on oxygen. Uniquely this bacterium is able to grow at temperatures as low as $1^{\circ} \mathrm{C}$ whereas most bacterium can only survive at this temperature, not grow [101].

The illness caused by consumption of L. monocytogenes is referred to as listeriosis and ranks third in deaths caused by foodborne pathogens. Listeriosis causes symptoms that include fever and diarrhea similar to other foodborne illnesses. Additionally, this bacterium can cause headaches, stiff neck, confusion, and loss of balance. Furthermore, pregnant women who become sick with listeriosis may experience miscarriage, still birth, premature delivery, and newborn infection. Individuals who are most commonly infected by this pathogen include pregnant women, newborns, elderly populations and the immunocompromised [102]. The Center for Disease Control and Prevention estimates that approximately 1,600 individuals suffer and 260 lose their life due to consumption of L. monocytogenes and subsequent listeriosis every year. The presence of Listeria monocytogenes has been found in peanuts, pecans, and mixed nuts $[96,103]$.

\section{Walnut and Pecan Product Recalls}

The detection of Salmonella, E. coli O157:H7, and Listeria monocytogenes in walnut and pecan samples has resulted in product recalls [104]. Examples of these recalls and the products affected are listed in the Table 1 below. 


\begin{tabular}{|c|c|c|c|c|c|}
\hline Pathogen & Commodity & Recall & $\begin{array}{c}\text { Foodborne } \\
\text { illnesses }\end{array}$ & Company & Reference(s) \\
\hline \multirow{12}{*}{ Salmonellaspp. } & Chopped walnuts & Yes & No & John B. Sanfilippo \& Son Inc. & 105,106 \\
\hline & $\begin{array}{l}\text { Walnut halves } \\
\text { and pieces }\end{array}$ & Yes & No & Gold State Nut Company & 106,107 \\
\hline & $\begin{array}{l}\text { Unsalted roasted } \\
\text { mixed nuts }\end{array}$ & Yes & No & Hannaford Supermarkets & 106,108 \\
\hline & $\begin{array}{l}\text { Walnut and trail } \\
\text { mix blend }\end{array}$ & Yes & No & Aurora Products, Inc & 106,109 \\
\hline & Raw walnuts & Yes & No & Trader Joe's Company & 106,110 \\
\hline & Pecan pieces & Yes & No & $\begin{array}{c}\text { Stone Mountain Pecan } \\
\text { Company }\end{array}$ & 106,111 \\
\hline & Walnut pieces & Yes & No & Eillien's Candies Inc. & 106,112 \\
\hline & $\begin{array}{c}\text { Chopped } \\
\text { Walnuts \& Pecan } \\
\text { Cookie Pieces }\end{array}$ & Yes & No & John B. Sanfilippo\& Son, Inc. & 106,113 \\
\hline & $\begin{array}{c}\text { Walnut Raw } \\
\text { Halves \& Pieces }\end{array}$ & Yes & No & Atlas Walnut, LLC & 106,114 \\
\hline & Pecan Pieces & Yes & No & American Pecan Co. & 115 \\
\hline & $\begin{array}{c}\text { Pecans in } \\
\text { Granola-Nut } \\
\text { Clusters }\end{array}$ & Yes & No & General Mills & 89 \\
\hline & $\begin{array}{c}\text { Unsalted Pecan } \\
\text { Pieces }\end{array}$ & Yes & No & John B. Sanfilippo\& Son & 106 \\
\hline \multirow[t]{2}{*}{$\begin{array}{l}\text { Shiga toxin } \\
\text { producing } E \text {. coli }\end{array}$} & $\begin{array}{c}\text { Raw Walnut } \\
\text { Halves \& Pieces }\end{array}$ & Yes & No & Johnvince Foods & 106,116 \\
\hline & Walnuts & Yes & 14 & Amira Enterprises & 106,116 \\
\hline \multirow{7}{*}{$\begin{array}{l}\text { Listeria } \\
\text { monocytogenes }\end{array}$} & $\begin{array}{c}\text { Walnut Trail } \\
\text { Mix }\end{array}$ & Yes & No & Cape Cod & 106,117 \\
\hline & Raw Walnuts & Yes & No & United Natural Trading LLC & 106,118 \\
\hline & Walnuts & Yes & No & Sherman Produce & 119 \\
\hline & Shelled Walnuts & Yes & No & Belleville Farmer's Market & 106,120 \\
\hline & Walnuts & Yes & No & Sun Tree LLC & 106,121 \\
\hline & $\begin{array}{l}\text { Mixed Nuts } \\
\text { Including } \\
\text { Walnuts and } \\
\text { Pecans }\end{array}$ & Yes & No & Lipari Foods, Inc. & 106 \\
\hline & Walnut Topping & Yes & No & John B. Sanfilippo \& Son Inc. & 106,122 \\
\hline
\end{tabular}

Table 1: Recalls and foodborne illnesses associated with pecans and walnuts

Pathogen Control Strategies used in Pecan and Walnut Industries

\section{Prevention on the Farm}

The pecan and walnut industries employ many interventions to reduce the likelihood of the production of contaminated food products. Good Agricultural Practices (G.A.P.s) are utilized to ensure that products produced meet both the quality and safety standards [123]. These practices exist to minimize situations that allow for bacterial survival and growth throughout the production of tree nuts. Examples of G.A.P. programs include, worker training, wildlife monitoring and sanitation. It has been stated that some G.A.P. programs are efficient to minimize infestation caused by fungi, but that they alone are not enough to eliminate microorganisms [124]. Additionally, voluntary third-party audit schemes such as USDA. G.A.P.'s and P.R.I.U.M.S. provide extra food safety protection for the food product. Farms that participate in these programs are required to maintain a more robust food safety management program to comply with these audit requirements. 


\section{Food Safety Modernization Act (FSMA)}

The primary objective of the Food Safety Modernization Act (FSMA) is to prevent food safety problems from occurring rather than react to events that have occurred [125127]. The FSMA provided the Food and Drug Administration (F.D.A.) with a legislative mandate allowing them to require science-based, comprehensive preventive controls across the food supply industry for the first time in history [128]. The FDAmaintains responsibility for the safety of both imported and domestic produce in the United States.

Seven rules are included within the FSMA:

- Produce Safety Rule

- Preventive Controls for Human Food

- Preventive Controls for Animal Food

- Foreign Supplier Verification Programs

- Accreditation of Third-Party Auditors/Certification Bodies

- Sanitary Transportation of Human and Animal Food

- Prevention of Intentional Contamination/Adulteration.

\section{The History of FSMA}

On January $4^{\text {th }}$, 2011, President Barak Obama signed the Food Safety Modernization Act (FSMA) into law [129]. FSMA was the largest food safety law reform that the United States had seen in over 70 years [130]. Under the FSMA rule, the authority held by the FDAwas expanded to grant them the legal right to: conduct mandatory recalls of known contaminated food products, enhance food borne illness outbreak surveillance systems, establish preventive controls and food safety plans in both farms and food-processing facilities, require enhanced FDAtraceability throughout the U.S. food distribution system, conduct more frequent inspections of high-risk food producing facilities, and an expansion of FDAauthority in regards to foreign suppliers of the U.S. [126].

\section{FSMA Produce Safety Rule and Preventive Controls for Human Foods Rule}

Two rules within FSMA which apply to the pecan and walnut industries are the Produce Safety Rule and the Preventive Controls for Human Foods Rule.

Since farms can never be considered zero-risk in relation to food product safety, the Produce Safety Rule within the FSMA aims at reducing food safety risks on the farm level and is the first federally mandated standard for the production of produce in the United States. This rule defines produce as "any fruit or vegetable (including mixes of intact fruits and vegetables) and includes mushrooms, sprouts (irrespective of seed source), peanuts, tree nuts, and herbs" [131]. Prior to the implementation of the Produce Safety Rule, a regulatory standard for growers did not exist; instead, those involved in the growing and processing of produce were only strongly encouraged to follow voluntary guidance documents.

Some produce products are exempt from the produce safety rule (112.2(a)) and include:

- Commodities that the FDA has identified as rarely consumed raw (including pecans).

- Produce strictly used for personal or on-farm consumption.

- 3. Produce that is not a raw agricultural commodity. A raw agricultural commodity is defined as any food that is in its raw or natural state.

The FSMA Preventive Controls for Human Food Rule is a requirement aimed at establishing preventive steps that food facilities can take to reduce or eliminate food safety hazards [132]. This rule includes the application of Current Good Manufacturing Practices (cGMPs), Hazard Analysis, and Risk-Based Preventive Controls [133].

The Hazard Analysis portion of the rule follows similar standards as are seen in Hazard Analysis and Critical Control Points (H.A.C.C.P.). H.A.C.C.P. is a preventative program aimed at reducing hazards. H.A.C.C.P. consists of seven principles: 1. Conduct a hazard analysis; 2 . Determine the critical control points; 3. Establish critical limits; 4. Establish monitoring system; 5. Establish corrective action; 6. Establish verification procedures; 7. Establish documentation and record keeping [134]. The determination of critical control points (C.C.P.s) is a crucial part of this program as it is the point at which interventions are implemented to reduce food safety risks [135]. In most cases, the determination of C.C.P.'s derives from a risk analysis. A risk analysis provides the food safety team with a look at the likelihood of occurrence of hazards. The Codex Alimentarius Commission defines a hazard as a biological, chemical or physical agent that may cause adverse health effects when consumed, whereas a risk is the hazards probability of occurrence [136]. Therefore, the seriousness of the hazard in relation to consumer health is determined by the interaction between a hazard and a risk $[135,137]$. Although, like the FSMA Preventive Controls for Human Food Rule, H.A.C.C.P. also focuses on prevention rather than response to food safety issues, H.A.C.C.P. has a primary focus on the implementation of processing controls (C.C.P.s). In addition to processing controls, the Preventive Controls for Human Food Rule places focus on allergen preventive controls, sanitation preventive controls, and supplier controls as well [138].

The Preventive Controls for Human Food rule applies to facilities that manufacture, process, pack, or hold human food products. Some facilities are excluded from this rule and include: farms, retail food businesses, very small businesses (< $\$ 1,000,000$ in a 3 year period), foods subject to H.A.C.C.P. 
(ex. seafood or juice), and low-acid canned food products [133].

\section{Development and Implementation of a FSMA Food Safety Plan}

It is important to note that a written food safety plan is a requirement of the Preventive Controls for Human Food rule but is not a requirement of the FSMA Produce Safety Rule. However, having this plan in place even if not required, can provide many benefits to the organization including food safety organization and can lead to the implementation of better practices to reduce the incidence of product hazards reaching the consumer. Successful company-wide food safety plan implementation is largely dependent on the organizations food safety culture which is mostly driven by management. It is crucial that managers and other food safety focused leaders adequately communicate relevant information to all employees involved in product manufacturing, processing, packaging or other direct food contact on a regular basis [125]. It is also important for food industry organizations to understand that a food safety plan should be treated as a "living document", meaning not only that what is written in the plan directly reflects practices being carried out, but also that it is constantly revised and updated as new information, products, or regulations are imposed or introduced [139]. This means that those who have a food safety plan in place must be flexible, adaptable, and open to frequent changes in both the written plan and in-plant practices.

The Code of Federal Regulations Title 21 part 117 describes the current good manufacturing practices, hazard analysis, and risk-based preventive controls for human food. Section 117.126 describes the F.D.A.'s requirements for food safety plans, required food safety plan contents, and records. The requirements are listed below and the contents of the food safety plan will be described in detail in the following paragraphs.

The requirements of the food safety plan are:

- Prepare and implement a food safety plan

- One or more preventive controls qualified individuals must prepare or oversee the preparation of the plan.

The food safety plan contents must include:

- Written hazard analysis (117.130(a)(2))

- Written preventive controls (117.135(b))

- Written supply-chain program (subpart G)

- Written recall plan (117.139(a))

- Written procedures for monitoring the implementation of preventive controls (117.145(a))

- Written corrective action procedures (117.150(a)(1))

- Written verification procedures (117.165(b))
The food safety plan records must include:

- Records that meets the requirements of subpart F

Written Hazard Analysis (117.130(a) (2))

21 CFR 117.130 describes the requirements for the written hazard analysis component of a food safety plan. This section of the code states, "you must conduct a hazard analysis to identify and evaluate, based on experience, illness data, scientific reports, and other information, known or reasonably foreseeable hazards for each type of food manufactured, processed, packed, or held at your facility to determine whether there are any hazards requiring a preventive control". Perhaps the most critical step in the preparation of a hazard analysis is the identification of hazards. If a hazard is missed during the creation of this document, it is impossible to perform an evaluation of it and therefore the determination of if a preventive control is applicable is not possible [139]. The types of hazards that should be included in the hazard analysis include biological hazards, chemical hazards, and physical hazards. Additionally, it is important to include hazards that occur naturally, those that may be unintentionally introduced to the food product, and hazards that could be intentionally introduced. Following the identification of potential hazards regarding the product, an evaluation of each hazard should be performed to determine the severity of potential illness or injury that the hazard could cause and the likelihood of the hazard occurring in the absence of the application of preventive controls. For those hazards which are deemed to require a preventive control, a written preventive control plan must be established.

\section{Written Preventive Controls (117.135(b))}

21 CFR 117.135 describes the requirements regarding preventive controls in a food safety plan. The purpose of preventive controls as described in the section are "...to provide assurances that any hazards requiring a preventive control will be significantly minimized or prevented and the food manufactured, processed, packed or held by your facility will not be adulterated...". Preventive controls can include process controls, food allergen controls, sanitation controls, supply-chain controls, recall plan, and any other control that is deemed necessary to satisfy the requirements. Process controls can include any procedures, practices, and processes implemented during product processing such as heat treatments, refrigeration, etc. Food allergen controls should include provisions that protect products from cross-contamination and ensure that product labelling is not misrepresentative of the food product. Sanitation controls include the processes, procedures, and practices that are employed to ensure that the food processing facility is sanitary to prevent hazards. Examples of sanitation controls include food contact surface cleanliness and allergen cross-contamination prevention. Supply-chain controls include the supply-chain program. The 
recall program is described in detail in 3.3c4. Examples of other types of controls include worker hygiene training and good manufacturing practices.

\section{Written Supply-Chain Program (Subpart G)}

The supply-chain program should evaluate the hazards that have the potential to occur prior to receiving the product. A determination then must be made regarding the hazards risk level and steps to be taken to minimize these risks.

\section{Written Recall Plan (117.139(a))}

21 CFR 117.139 describes the recall plan requirements for the food safety plan and states that a written recall plan must be created for any food product that has hazards which require the implementation of a preventive control. The code states that a recall plan is required to include procedures that describe steps to be taken and assign responsibility to individuals responsible for taking the steps. In addition, the organization must notify the public and those who have received the product about appropriate steps to handle the food such as returning or disposing of the product. In order to verify that a recall has been successful, effectiveness checks should be conducted.

\section{Written Procedures for Monitoring the Implementation of Preventive Controls (117.145(a))}

21 CFR 117.145 describes requirements for monitoring in regard to preventive controls. Written procedures must be established and implemented and the frequency at which they are to be performed must be specified. The frequency specified should be adequate to assure that the monitoring procedures are consistently performed.

\section{Written corrective action procedures (117.150 (a) (1))}

21 CFR 117.150 states that if preventive controls are not implemented properly, corrective actions must be taken. An example of this would be if a pathogenic microorganism is detected following all preventive controls. Corrective action procedures should be written to ensure that actions are taken to identify and correct problems, the likelihood of problem recurrence is minimized, food products affected by the problem are evaluated for safety, and any food found to be affected by the problem does not enter commerce.

\section{Written Verification Procedures (117.165(b))}

21 CFR 117.160 describes the requirements for written verification procedures. The verification procedures should ensure that monitoring is being conducted as required, corrective actions are appropriate, the implementation and effectiveness of the food safety plan, and reanalysis is done in accordance with 117.170. Additionally, all verification activities that are conducted must be documented and the documents maintained in records.

\section{Records (117.190)}

Records must be established and maintained to meet the requirements of 21 CFR 117.190.

Records required include:

- Documentation of monitoring of preventive controls

- Documentation of corrective actions

- Documentation of verification including validation, verification of monitoring, verification of corrective actions, calibration of process monitoring and verification instruments, product testing, environmental monitoring, records review, and reanalysis

- Documentation of the supply-chain program

- Documentation of preventive controls qualified individual and qualified auditor training

\section{Advantages of an FSMA Food Safety Plan}

A FSMA Food Safety Plan has been found to be a crucial part of the effective implementation of produce safety practices and is a requirement for nut shellers. A food safety plan provides a look at the food production or processing facility from all safety angles. This allows those involved in any aspect of food safety to ensure that they have identified potential risks or hazards and are implementing proper actions to minimize them. Furthermore, a farm food safety plan is a requirement of third-party audits and provides a source of documentation that can be provided to officials, if needed to prove compliance with state and federal regulations. When appropriately developed and implemented, a FSMA food safety plan can be an effective tool in the protection of consumers from food hazards and avoidance of liability for the food grower or processor [139].

\section{Commonly used Antimicrobials}

Walnuts and pecans are often washed by submersion in a tank of water, sometimes with antimicrobials added or with thermal processes implemented. These water baths that are utilized have the effect of washing which can diminish bacterial load. However, the wash water itself can also allow for cross-contamination among batches of nuts. Therefore, the water temperature, antimicrobial, or combination of both used in the wash water itself is a vital component of nut food safety. Some examples of antimicrobial additions to wash water in the nut industry include, chlorine, peracetic acid (PAA.), E.O. water, and organic acids. Walnut processors may also use processes such as propylene oxide and steam treatments [140]. 


\section{Chlorine}

Chlorinated water is used as an additive in wash water to sanitize in-shell nuts. The treatment of fresh produce using water with chlorine added has shown to be effective in the reduction of foodborne pathogens from food products [141]. In fact, the most used chemical water additive to remove bacterial contaminants from produce is chlorinated water [142, 143]. The application of chlorine in the nut industry is approved for concentrations up to 1000PPM [144]. However, the effectiveness of chlorine is reduced when it exposed to the varying conditions in-shell nut washing can impose. Some effects caused by this reduction in effectiveness are reduced efficacy after rinsing, potential cross-contamination, and sensitivity to temperature and organic load [145]. The effectiveness of chlorine is reduced whenever it is exposed to nitrogenous compounds of foods and can further result in the formation of halogenated organic compounds [146]. The use of chlorine also poses a risk to produce harmful byproducts when chlorine interacts with organic material such as chloramines, trihalomethanes and other organochlorine compounds. This is of major concern due to their health implications and carcinogenic properties [147]. Therefore, a rising number of consumer safety concerns about the use of chlorine as an antimicrobial have been raised, and alternatives to chlorine continue to be investigated.

\section{Peracetic acid}

Peracetic acid (PAA) is a solution derived from the reaction of hydrogen peroxide and acetic acid [148]. PAA. is an effective antimicrobial that loses effectiveness slowly in the presence of organic matter [149-151]. Therefore, in comparison to chlorine sanitation, PAA. is more suited for the nut industry due to its antimicrobial stability under varying conditions such as dirt and debris that the introduction of inshell nuts imposes on the wash water [152]. The maximum residue of PAA. allowed in produce wash water has been set by the FDA at 80PPM [153]. This limit is a limitation as studies have shown this concentration is not sufficient to achieve desired microbial reductions. One study found that when a 500PPM PAA. solution was used on laboratory inoculated in-shell almonds with Salmonella, a $1.27 \log$ unit reduction was achieved [154]. PAA. is an acceptable option for a nut wash water sanitizer, however its vulnerability to high organic load is troubling for this application $[\mathbf{1 5 5}, \mathbf{1 5 6}]$. Moreover, many states have imposed regulations which restrict the discharge of certain sanitizers into the drainage systems and environment.

\section{Hot Water}

Hot water antimicrobial treatments are often used in the nut industry. The requirements listed by the Oklahoma Health Department Food Processing Code 310:260 subchapters 5 specify that first, the nut should be cleaned thoroughly to remove any foreign matter. Then the pecan must be subjected to either immersion for at least two minutes in water that is at least 170 degrees F., or in a flow of water at least this temperature for 5 minutes. However, maintaining water at this temperature has proven to produce a large amount of steam which translates into an issue for food processing facilities. The steam builds up on walls and ceilings and can lead to mold growth. Additionally, the increased humidity in the processing environment could induce mold growth on in-shell nuts. Consequently, the use of hot water as a sanitizing treatment in the nut industry is not ideal.

\section{Organic Acids}

Another category of sanitizers that can be effectively employed in the nut processing industry to inhibit pathogen growth are organic acids. Acetic acid, citric acid, lactic acid, malic acid, propionic acid, succinic acid, and tartaric acid are examples of organic acids that can be used in the food processing industry [157]. Organic acids are natural antimicrobials that work by increasing anion accumulation and decreasing the $\mathrm{pH}$ of the cell and the environment [158]. One study found that immersion of Salmonella inoculated in-shell pecans in a $2 \%$ lactic acid solution for 2 minutes resulted in a 3-log CFU/g reduction [159].

\section{Sodium Acid Sulfate and Potassium Acid Sulfate}

Sodium acid sulfate (S.A.S.) is a naturally derived food acid also referred to as, sodium bisulfate, bisulfate of soda or sodium hydrogen sulfate and has a chemical formula of NaHSO4 [160]. S.A.S. has generally recognized as safe (G.R.A.S.) status issued by the FDA for use as a surface sanitizer. Due to S.A.S.'s safety both in human health and the environment, the Environmental Protection Agency (E.P.A.) has listed S.A.S. as a "safer choice" antimicrobial (https://www.epa.gov/saferchoice/saferingredients\#searchList) . S.A.S. has been used in the processing of fresh fruits and vegetables because of its anti-browning effects, specifically in fresh cut apples and potatoes [161]. Other products that S.A.S. has been included in include sauces, dressings, soups, prepared meals, beverages, dips, fillings, gravies, spreads, and desserts. One unique property of S.A.S. is its ability to reduce the $\mathrm{pH}$ of food products without producing a sour taste. However, there is little research available of S.A.S.'s antimicrobial capabilities. The use of S.A.S. as an antimicrobial agent has been explored briefly for whole chicken drumsticks, apples, and chicken carcasses $[162,163]$. The potential application of S.A.S. as an antimicrobial for use in the food industry continues to be explored. Potassium acid sulfate (K.A.S.) or potassium bisulfateis novel to the food industry, and little is known of its antimicrobial effectiveness at this point. Currently, there is nothing available in the literature documenting K.A.S. as an antimicrobial agent. However, its popularity is growing due to an increased demand for sodium alternative ingredients in the food industry. A previously 
conducted study found that S.A.S. and K.A.S. employ a multifaceted approach to inactivate both Gram-negative and Gram-positive pathogens which could give their use a significant advantage over other commonly utilized antimicrobials [164].

\section{Other}

In addition to the above antimicrobials, many proprietary sanitizers exist and are utilized consisting of different concentrations and mixtures of each. Additional antimicrobials are also used but are not necessarily common. Continued research into the efficacy and limitations of these and new antimicrobials is required to continue improvement of in-shell nut handling and decontamination practices within the food industry.

\section{Conclusion}

Pecan and walnut are two specialty crops of great economic importance to the U.S. There are numerous foodborne illnesses outbreaks and recalls associated with pecan and walnuts. The nut industry had made significant progress toward improving the microbial safety of their products by impaneling pre and post-harvest crop management practices. Implementation of robust food safety and quality management program in combination with effective post-harvest antimicrobial interventions could significantly improve the overall safety and profitability of pecan and walnut industries.

\section{References}

1. USDA., E.R.S. (2020) Per capita consumption of tree nuts (shelled) in the United States from 2000 to 2018 (in pounds). Statista.

2. Vadivel VPD, Kunyanga C, Biesalski H (2012) Health benefits of nut consumption with special reference to body weight control. Nutrition 28: 1089-1097.

3. Atanasov AG, Sabharanjak SM, Zengin G, Mollica A, Szostak A, et al. (2018) Pecan nuts: A review of reported bioactivities and health effects. Trends in Food Science \& Technology 71: 246-257.

4. Hal GD (2000) Pecan food potential in prehistoric North America. Economic botany 54: 103-112.

5. Villarreal-Lozoya JE, Lombardini L, Cisneros-Zevallos L (2007) Phytochemical constituents and antioxidant capacity of different pecan [Caryaillinoinensis (Wangenh.) K. Koch] cultivars. Food Chemistry 102: 1241-1249.

6. USDA ARS (2021) "Caryaillinoinensis". Germplasm Resources Information Network (GRIN).

7. A\&M (2006) Pecan Kernel. T.A.M.U.

8. Little EL (1978) Important forest trees of the United States. Forest Service, USDA.

9. Markle GM, Baron JJ, Schneider BA, Moses L (1998) Food and Feed Crops of the United States Edition 2
10. Thomas SE (1972) The genera of Juglandaceae in the southeastern United States. Journal of the Arnold Arboretum 53: 26-51.

11. USDA ERS. Georgia is the leading U.S. producer of pecans 2015.

12. Prabhakar H, Sharma S, Kong F (2020) Effects of postharvest handling and storage on pecan quality. Food Reviews International p. 1-28.

13. Heaton EK, Woodroof JG (1970) Humidity and weight loss in cold stored pecans. ASHRAE 12: 49-51.

14. Ryan E, Galvin $K$, O'Connor TP, Maguire AR, O'Brien NM (2006) Fatty acid profile, tocopherol, squalene and phytosterol content of brazil, pecan, pine, pistachio and cashew nuts. International Journal of Food Sciences and Nutrition 57: 219-228.

15. Venkatachalam M, Sathe S (2006) Chemical Composition of Selected Edible Nut Seeds. Journal of Agricultural and Food Chemistry 54: 4705-4714.

16. Salas-Salvadó J, Guasch-Ferré M, Bullo M, et al. (2014) Nuts in the prevention and treatment of metabolic syndrome. The American Journal of Clinical Nutrition 100: 399-407.

17. Sabate J, Oda K, Ros E (2010) Nut Consumption and Blood Lipid Levels: A Pooled Analysis of 25 Intervention Trials. Archives of Internal Medicine 170: 821-827.

18. Sabate J, Wien M (2010) Nuts, blood lipids and cardiovascular disease. Asia Pacific Journal of Clinical Nutrition 19: 131-136.

19. Wu X, Beecher GR, Holden JM, Haytowitz DB, Gebhardt SE, et al. (2004) Lipophilic and hydrophilic antioxidant capacities of common foods in the United States. Journal of Agricultural and Food Chemistry 52: 4026-4037.

20. Bravo L (1998) Polyphenols: chemistry dietary sources, metabolism, and nutritional significance. Nutrition Review 56: 317-333.

21. Jahanban-Esfahlan A, Ostadrahimi A, Tabibiazar $M$, Amarowicz R (2019) A comparative review on the extraction, antioxidant content and antioxidant potential of different parts of walnut (Juglans regia L.) fruit and tree. Molecules 24: 2133.

22. Ruhmann S, Leser C, Bannert M, Treutter D (2002) Relationship between growth, secondary metabolism, and resistance of apple. Plant Biology 4: 137-143.

23. Treutter D (2001) Biosynthesis of phenolic compounds and its regulation in apple. Plant Growth Regulation 34: 71-89.

24. Treutter D (2006) Significance of flavonoids in plant resistance: a review. Environmental Chemistry Letters 4: 147-157.

25. Martillanes S, Rocha-Pimienta $J$, Cabrera-Bañegil $M$, Martín-Vertedor, Delgado-Adámez J (2017) Application of phenolic compounds for food preservation: food additive and active packaging. IntechOpen.

26. Quan W, He W, Lu M, Yuan B (2019) Anthocyanin composition and storage degradation kinetics of anthocyanins- based natural food colourant from 
purple- fleshed sweet potato. International Journal of Food Science \& Technology 54: 2529-2539.

27. Scalbert A, Johnson IT, Saltmarsh M (2005) Polyphenols: antioxidants and beyond. The American Journal of Clinical Nutrition 81: 215-217.

28. Anderson KJ, Teuber SS, Gobeille A, Cremin P, Waterhouse AL, et al. (2001) Walnut polyphenolics inhibit in vitro human plasma and LDL oxidation. The Journal of Nutrition 131: 2837-2842.

29. Carvalho M, Ferreira PJ, Mendes VS, Silva R, Pereira JA, et al. (2010) Human cancer cell antiproliferative and antioxidant activities of Juglans regia L. Food and Chemical Toxicology 48: 441-447.

30. Li AN, Li S, Zhang YJ , Xu XR, Chen YM, et al. (2014) Resources and biological activities of natural polyphenols. Nutrients 6: 6020-6047.

31. Manach C, Scalbert A, Morand C, Rémésy C, Jiménez L (2004) Polyphenols: food sources and bioavailability. The American Journal of Clinical Nutrition 79: 727-747.

32. Peng C, Wang X, Chen J, Jiao R, Wang L, et al. (2014) Biology of ageing and role of dietary antioxidants. BioMed Research International 83: 1-13.

33. Wojtunik-Kulesza KA, Oniszczuk A, Oniszczuk T, Waksmundzka-Hajnos M (2015) The influence of common free radicals and antioxidants on development of Alzheimer's Disease. Biomedicine \& Pharmacotherapy 78: 39-49.

34. Xu DP, Li Y, Meng X, Zhou T, Zhouet Y, al. (2017) Natural antioxidants in foods and medicinal plants: extraction, assessment and resources. International Journal of Molecular Sciences 18: 96.

35. Zhang YJ, Ren-You Gan RY, Li S, Zhou Y, Li AN, et al. (2015) Antioxidant phytochemicals for the prevention and treatment of chronic diseases. Molecules 20: 2113821156.

36. Zhou Y, Li Y, Zhou T, Zheng J, Li S, et al. (2016) Dietary natural products for prevention and treatment of liver cancer. Nutrients 8: 156.

37. Zhou Y, Zheng J, Li Y, Xu DP, Li S, et al. (2016) Natural polyphenols for prevention and treatment of cancer. Nutrients 8: 515.

38. Martinez M, Labuckas DO, Lamarque AL, Maestri DM (2010) Walnut (Juglans regia L.): genetic resources, chemistry, by-products. Journal of the Science of Food and Agriculture 90: 1959-1967.

39. Elias TS (1980) The complete trees of North America: field guide and natural history. Outdoor Life/Nature Books.

40. Peattie DC (1966) A natural history of trees of eastern and central North America. Houghton Mifflin Co.

41. Petrides GA (1998) Eastern trees. Houghton Mifflin Co.

42. Blessington T, Mitcham E, Harris L (2012) Survival of Salmonella enterica, Escherichia coli O157:H7, and Listeria monocytogenes on inoculated walnut kernels during storage. Journal of Food Protection 75: 245-254.
43. ERS. (2008) Fruit and tree nuts situation and outlook yearbook. United States Department of Agriculture, Economic Research Service.

44. USDA. Tree nuts: world markets and trade. United States Department of Agriculture, Foreign Agricultural Service.

45. California Walnut Board. (2017) Monthly management reports.

46. Blessington T, Mitcham E, Harris L (2014) Growth and survival of enterobacteriaceae and inoculated Salmonella on walnut hulls and maturing walnut fruit. Journal of Food Protection 77: 1462-1470.

47. Blessington T, Mitcham E, Harris L (2012) Survival of Salmonella enterica, Escherichia coli O157:H7, and Listeria monocytogenes on inoculated walnut kernels during storage. Journal of Food Protection 75: 245-254.

48. Frelka J, Davidson G, Harris L (2016) Changes in aerobic plate and Escherichia coli coliform counts and in populations of inoculated foodborne pathogens on inshell walnuts during storage. Journal of Food Protection 79: 1143-1153.

49. Santillana-Farakos SM, Pouillot R, Davidson GR, Johnson R, Son I, et al. (2019) A quantitative risk assessment of human salmonellosis from consumption of walnuts in the United States. Journal of Food Protection 82: 45-57.

50. Hepburn FN, Exler J, Weihrauch JL (1986) Provisional table on the content of omega-3 fatty acids and other fat components in selected foods. USDA. Publication HNIS/PT-103.

51. Linda CT, Gillen LJ, Patch CS, Batterham M, Owen A, et al. (2004) Including walnuts in a low-fat/modified-fat diet improves HDL cholesterol-to-total cholesterol ratios in patients with type 2 diabetes. Diabetes Care 27: 27772783.

52. Davis L, Stonehouse W, Loots DT, Mukuddem-Petersen J, van der Westhuizen HF, et al. (2007) The effects of high walnut and cashew nut diets on the antioxidant status of subjects with metabolic syndrome. European Journal of Nutrition 46: 155-164.

53. Lavedrine F, Zmirou D, Ravel A, Balducci F, Alary J (1999) Blood cholesterol and walnut consumption: a cross-sectional survey in France. Preventive Medicine 28: 333-339.

54. Ros E, Núñez I, Pérez-Heras A, Serra M, Gilabert R, et al. (2004) A Walnut diet improves endothelial function in hypercholesterolemic subjects: A randomized crossover trial. Circulation 109: 1609-1614.

55. Zhao G, Etherton TD, Martin KR, West SG, Gillies PJ, et al. (2004) Dietary [alpha]-Linolenic acid reduces inflammatory and lipid cardiovascular risk factors in hypercholesterolemic men and women. The Journal of Nutrition 134: 2991.

56. Poulose SM, Miller M, Shukitt-Hale B (2014) Role of walnuts in maintaining brain health with age. The Journal of Nutrition 144: 561-566. 
57. Chen Y, et al. (2009) Control of Salmonella in lowmoisture foods.

58. Chipley JR, Heaton E (1971) Microbial flora of pecan meat. Applied Microbiology 22: 252-253.

59. Kajs TM, Hagenmaier R, Vanderzant C, Mattil KF (1976) Microbiological evaluation of coconut and coconut products. Journal of Food Science 41: 352-356.

60. Meyer MT, Vaughn R (1969) Incidence of Escherichia coli in black walnut meats. Applied Microbiology 18: 925-931.

61. Beuchat LR, Heaton E (1975) Salmonella survival on pecans as influenced by processing and storage conditions. Applied Microbioloogy 29: 795-801.

62. Beuchat LR, Mann D (2010) Factors affecting infiltration and survival of Salmonella on in-shell pecans and pecan nutmeats. Journal of Food Protection 73: 1257-1268.

63. Danyluk MD, Brandl M, Harris L (2008) Migration of Salmonella enteritidis phage type 30 through almond hulls and shells. Journal of Food Protection 71: 397-401.

64. King AD, Mary J, Linda C (1970) Almond harvesting, processing, and microbial flora. Applied Microbiology 20: 208.

65. Marcus KA, Amling H (1973) Escherichia coli field contamination of pecan nuts. Applied Microbiology 26: 279-281.

66. Blessington T, Theofel CG, Mitcham EJ, Harris LJ (2013) Survival of foodborne pathogens on inshell walnuts. International Journal of Food Microbiology 166: 341-349.

67. Blessington $\mathrm{T}$ (2011) A microbiological hazard analysis of California walnut production and handling. ProQuest Dissertations Publishing.

68. Cosby DE, Cox NA, Harrison MA, Wilson JL, Buhr JR, et al. (2015) Salmonella and antimicrobial resistance in broilers: A review. Journal of Applied Poultry Research 24: 408-426.

69. Costerton JW, Lewandowski Z, DeBeer D, Caldwell D, Korber D, et al. (1994) Biofilms, the customized microniche. The Journal of Bacteriology 176: 2137.

70. Costerton JW, Lewandowski Z, Caldwell DE, Korber DR, Lappin-Scott HM (1995) Microbial biofilms. Annual Review of Microbiology 49: 711-745.

71. Laufer AS, Grass J, Holt K, Whichard JM, Griffin PM, et al. (2015) Outbreaks of Salmonella infections attributed to beef - United States, 1973-2011. Epidemiological Infections 143: 2003-2013.

72. Centers for Disease Control and Prevention. (2008) Salmonellosis.

73. Lee L, Metz D, Giovanni M, Bruhn CM (2011) Consumer knowledge and handling of tree nuts: food safety implications. Food Protection Trends 31: 18-27.

74. Burnett S, Gehm ER, Weissinger WR, Beuchat LR (2000) Survival of Salmonella in peanut butter and peanut butter spread. Journal of Applied Microbiology 89: 472-477.

75. Kilonzo-Nthenge A, Rotich E, Godwi S, Huang T (2009) Consumer storage period and temperature for peanut butter and their effects on survival of Salmonella and
Escherichia coli O157:H7. Food Protection Trends 29: 787.

76. Reiji H, Matsumoto M, Sakae K, Miyazaki Y (2005) Ability of shiga toxin-producing Escherichia coli and Salmonella spp. to survive in a desiccation model system and in dry foods. Applied and Environmental Microbiology 71: 6657-6663.

77. Rehm C, Drewnowski A (2017) Replacing American snacks with tree nuts increases consumption of key nutrients among U.S. children and adults: results of an N.H.A.N.E.S. modeling study. Nutrition Journal.

78. Uesugi AR, Danyluk MD, Harris L (2006) Survival of Salmonella Enteritidis phage type 30 on inoculated almonds stored at $-20,4,23$, and $35^{\circ} \mathrm{C}$. Journal of Food Progection 69: 1851-1857.

79. Lin BH, Frazao E, Allshouse J (2001) U.S. consumption patterns of tree nuts. Food Review 24: 54.

80. Frankel EN. (2005) Lipid oxidation. The Oily Press.

81. Ma L, Zhang G, Gerner-Smidt P, Mantripragada V, Ezeoke I, et al. (2009) Thermal inactivation of Salmonella in peanut butter. Journal of Food Protection 72: 15961601.

82. Juneja VK, Eblen B, Ransom G (2001) Thermal inactivation of Salmonella spp. in chicken broth, beef, pork, turkey, and chicken: determination of $\mathrm{d}-$ and Z- values. Journal of Food Science 66: 146-152.

83. Manas $\mathrm{P}$, Pagan R, Leguérinel I, Condon $\mathrm{S}$, Mafart $\mathrm{P}$, et al. (2001) Effect of sodium chloride concentration on the heat resistance and recovery of SalmonellaTyphimurium. International Journal of Food Microbiology 63: 209-216.

84. Waterman SR, Small P. (1998) Acid-sensitive enteric pathogens are protected from killing under extremely acidic conditions of ph 2.5 when they are inoculated onto certain solid food sources. Applied Environmental Microbiology 64: 3882-3886.

85. Mclinden T, Sargeant JM, Thomas MK, Papadopoulos A, Fazil A, et al. (2014) Association between component costs, study methodologies, and foodborne illness-related factors with the cost of nontyphoidal Salmonella illness. Foodborne Pathogens and Disease 11: 718-726.

86. CDC. (2003-2004) Outbreak of Salmonella serotype Enteritidis infections associated with raw almondsUnited States and Canada. More Mortal. Weekly Report. 53:484-487.

87. FDA. (2009) Willamette shelling recalls shelled hazelnuts because of possible health risk.

88. CDC.(2009) Salmonella in pistachio nuts.

89. FDA. (2009) General Mills announces voluntary recall of limited quantity of 'Nut Lovers' flavor of nature valley granola nut clusters product.

90. Palumbo M, Beuchat LR, Danyluk MD, Harris LJ (2016) Recalls of tree nuts and peanuts in the U.S., 2001-present [Table and references]. In U.S. recalls of nuts.

91. Meng J, Zhao S, Doyle M (1998) Virulence genes of Shiga toxin-producing Escherichia coli isolated from 
food, animals and humans. International Journal of Food Microbiology 45: 229-235.

92. Hoffmann S, Maculloch B, Batz M (2015) Economic burden of major foodborne illnesses acquired in the United States. Current Politics and Economics of the United States, Canada and Mexico 17: 543-616.

93. Cassin MH, Lammerding AM, Todd EC, Ross W, McColl RS (1998) Quantitative risk assessment for Escherichia coli $\mathrm{O} 157: \mathrm{H} 7$ in ground beef hamburgers. International Journal of Food Microbiology 41: 21-44.

94. Law D (2000) Virulence factors of Escherichia coli $\mathrm{O} 157$ and other Shiga toxin-producing E. coli. Oxford 88: 729745 .

95. Nazareth JR (2017) Prevalence of Salmonella species and Escherichia Coli O157:H7 in organically managed cattle and food safety status of selected meat products. Iowa State University Digital Repository.

96. Brar PK, et al. (2015) Survival of Salmonella, Escherichia coli O157:H7, and Listeria monocytogenes on raw peanut and pecan kernels stored at -24 , 4, and $22^{\circ} \mathrm{C}$. Journal of Food Protection 78: 323-332.

97. Davidson G, Frelka JC, Yang YM, Jones TM, Harris LJ (2015) Prevalence of Escherichia coli O157:H7 and Salmonella on inshell California walnuts. Journal of Food Protection 78: 1547-1553.

98. Miksch RR, Leek J, Myoda S, Nguyen T, Tenney K, et al. (2013) Prevalence and counts of Salmonella and enterohemorrhagic Escherichia coli in raw, shelled runner peanuts. Journal of Food Protection 76(10): 1668-1675.

99. Upadhyay A, Upadhyaya I, Mooyottu S, Kollanoor-Johny A, Venkitanarayanan K (2014) Efficacy of plant-derived compounds combined with hydrogen peroxide as antimicrobial wash and coating treatment for reducing Listeria monocytogenes on cantaloupes. Food Microbiology 44: 47-53.

100.Kataoka A, Wang H, Elliott PH, Whiting RC, Hayman MM (2017) Growth of Listeria monocytogenes in thawed frozen foods. Journal of Food Protection 80: 447-453.

101.Burall LS, Laksanalami P, Datta A (2012) Listeria monocytogenes mutants with altered growth phenotypes at refrigeration temperature and high salt concentrations. Applied and Environmental Microbiology 78: 1265-1272.

102. Gaul LK, Farag NH, Shim T, Kingsley MA, Silk BJ, et al. (2013) Hospital-acquired listeriosis outbreak caused by contaminated diced celery--Texas, 2010. Clinical infectious diseases : an official publication of the Infectious Diseases Society of America 56: 20.

103.Eglezos S (2010) The bacteriological quality of retaillevel peanut, almond, cashew, hazelnut, brazil, and mixed nut kernels produced in two Australian nut-processing facilities over a period of 3 years. Foodborne Pathogens and Disease 7: 863-866.

104.Palumbo M, Beuchat LR, Danyluk MD, Harris LJ (2014) Recalls of tree nuts and peanuts in the U.S., 2001 to present, table and references. In U.S. recalls of nuts.
105.Falkenstein D (2015) Fisher Nuts Recalled for Salmonella- Again. Food Poison Journal. Food Poisoning Outbreaks and Litigation: Surveillance and Analysis.

106. Yada S, Harris L (2019) Recalls of tree nuts and peanuts in the U.S., 2001 to present (version2) [Table and references]. In U.S. recalls of nuts.

107.FSN (2015) Hines Walnut Halves \& Pieces Recalled for Salmonella Risk. Food Safety News News Desk.

108.Pritzker F (2015) Hannaford Recalls Nature's Place Mixed Nuts for Salmonella. Food Poisoning Bulletin.

109.FSN (2015) Giant and Martin's Brand Walnuts and Trail Mixes Recalled for Salmonella Risk. Food Safety News News Desk.

110.FSN (2015) Trader Joe's Recalls Raw Walnuts Due to Possible Salmonella Contamination. Food Safety News News Desk.

111.GDA (2015) Georgia company recalls certain pecan products due to possible health risk. Georgia Department of Agriculture Press Release.

112.Laasby G (2015) Recall of walnut pieces from Eillien's Candies, Piggly Wiggly, Blain's Farm and Fleet and Mills Fleet Farm for possible Salmonella. Milwaukee Journal Sentinel.

113.FDA(2014) John B Sanfilippo \& Son, Inc. Voluntarily Recalls Fisher Brand 8 oz. Chopped Walnuts and Fisher Brand 8 oz. Pecan Cookie Pieces Because of Possible Health Risk. FDARecall -- Firm Press Release.

114.Caywood C (2010) Atlas Walnut Company Recalls Walnuts for Salmonella Risk. Food Poison Journal. Food Poisoning Outbreaks and Litigation: Surveillance and Analysis. Posted in: Foodborne Illness Outbreaks.

115.Flynn D. (2010) American Pecan Recalls 1 lb Bags. Food Safety News.

116.FSN (2011) Another Canada Recall of U.S. Walnuts. Food Safety News News Desk.

117.FSN (2016) More walnuts recalled because of potential Listeria. Food Safety News News Desk.

118.FDA (2016) United Natural Trading L.L.C. Announces Voluntary Recall of Walnuts. U.S. Recall News.

119.FSN. (2014) Walnuts Recalled Due to Potential Listeria Contamination. Food Safety News News Desk.

120.FSN (2014) Illinois Firm Recalls Shelled Walnuts for Potential Listeria. Food Safety News News Desk.

121.FSN (2014) Phoenix Company Announces Walnut Recall, Names California Distributor. Food Safety News News Desk.

122. Clark M. (2009) John B. Salfilippo \& Son Inc., Recalls Listeria Walnuts. Marler Clark, The Food Safety Law Firm. Listeria Blog. Surveillance \& Analysis on Listeria News and Outbreaks. Posted in Listeria Recalls.

123. Gorayeb TC, Casciatori PF, Bianchi VLD, Thoméo JC (2009) HACCP plan proposal for a typical Brazilian peanut processing company. Food Control 16: 511-514.

124. Sperber WH (2005) HACCP. does not work from farm to table. Food Control 16: 511-514. 
125.Jack P (2016) FSMA Compliance: Tips to Avoid 'Analysis Paralysis' in Mid-Size Companies. Food Manufacturing.

126.Johnson M (2018) An end user perspective: the impact of FSMA on restaurants. Cornell Hospitality Quarterly 59: 85-92.

127.Stewart K, Gostin L (2011) Food and Drug Administration Regulation of Food Safety. The Journal of the American Medical Association 306: 88-89.

128.FDA Background on the FDA Food Safety Modernization Act (FSMA).

129. Overdiep I (2018) Implementation of the Food Safety Modernization Act among fruit and vegetable processors in the North Central Region: Iowa State University Digital Repository.

130.Lloyd S (2013) FSMA and its impact on the beverage industry. Beverage Industry 104: 72.

131.FDAFDAFact Sheet- Produce Safety Rule (21 CFR 112): FDA PDF.

132.FDAKey Facts about Preventive Controls for Human Food. U.S. Food and Drug Administration.

133. Arteaga A (2017) International development and capacity building for the implementation of food safety regulations in produce: A focus on the Food Safety Modernization Act.

134.Codex Alimentarius Commission. (2004) Code of practice for the prevention and reduction of aflatoxin contamination in peanuts. C.A.C.R.C.P. 55. www.codexalimentarius.net.

135. Bertolini M, Rizzi A, Bevilacqua M (2007) An alternative approach to HACCP system implementation. Journal of Food Engineering 79: 1322-1328.

136.CAC. (1999) Recommended Methods of Analysis and Sampling. CODEX STAN 234.

137. Ross T, Sumner J (2002) A simple, spreadsheet-based, food safety risk assessment tool. International Journal of Food Microbiology 77: 39-53.

138. Barach JT (2017) FSMA and food safety systems: understanding and implementing the rules. John Wiley \& Sons, Incorporated.

139. Neltner T. (2017) Identifying chemical hazards for FSMA food safety plan. Refrigerated \& Frozen Foods 27(7): 15

140.Ivarsson C (2013) Validation of processes for reducing the microbial load on nuts. Food Science, Technology and Nutrition 148-170.

141. Beuchat LR. (2000) Use of sanitizers in raw fruit and vegetable processing. In Minimally Processed Fruits and Vegetables 63-78.

142. Shen C, Luo Y, Nou X, Bauchan G, Zhou B, et al. (2012) Enhanced inactivation of Salmonella and Pseudomonas biofilms on stainless steel by use of $\mathrm{t}-128$, a fresh-produce washing aid, in chlorinated wash solutions. Applied and Environmental Microbiology 78: 6789.

143. Weissinger WR, Chantarapanont W, Beuchat L (2000) Survival and growth of Salmonella baildon in shredded lettuce and diced tomatoes, and effectiveness of chlorinated water as a sanitizer. International Journal of Food Microbiology 62: 123-131.

144.O.S.D.H. Pecan Processing. Oklahoma State Department of Health. Oklahoma Administrative Code for Good Manufacturing Practice Regulations Sub-chapter 5, Pecan Processing.

145.Goodburn C, Wallace C (2012) The microbiological efficacy of decontamination methodologies for fresh produce: A review. Food Control 32: 418-427.

146. Wei CI, Cook D, Kirk J (1985) Use of chlorine compounds in the food industry. Food Technology 39: 107-115.

147.Zhang S, Farber J (1996) The effects of various disinfectants against Listeria monocytogenes on fresh-cut vegetables. Food Microbiology 13: 311-321.

148. Weller LD, Daeschel MA, Durham CA, Morrissey MT (2013) Effects of water, sodium hypochlorite, peroxyacetic acid, and acidified sodium chlorite on in- shell hazelnuts inoculated with Salmonella enterica serovar panama. Journal of Food Science 78: 1885-1891.

149.Gomez-Lopez VM, Rajkovic A, Ragaert P, Smigic N, Devlieghere F (2009) Chlorine dioxide for minimally processed produce preservation: a review. Trends in Food Science \& Technology 20: 17-26.

150.VanDeVelde F, Guemes D, Pirovani M (2014) Optimisation of the peracetic acid washing disinfection of fresh- cut strawberries based on microbial load reduction and bioactive compounds retention. International Journal of Food Science and Technology 49: 634-640.

151. Vandekinderen I, Devlieghere F, Meulenaer BD, Ragaert P, Van Camp J (2009) Optimization and evaluation of a decontamination step with peroxyacetic acid for fresh-cut produce. Food Microbiology 26: 882-888.

152.Ruiz-Cruz S, Acedo-Félix E, Díaz-Cinco M, Islas-Osuna MA, González-Aguilar GA (2007) Efficacy of sanitizers in reducing Escherichia coli O157:H7, Salmonella spp. and Listeria monocytogenes populations on fresh-cut carrots. Food Control 18: 1383-1390.

153.FDA. (2012) Chemicals used in washing or to assist in the peeling of fruits and vegetables. 21 CFR 173.315.

154.Pao S, Kalantari A, Huang G (2006) Utilizing acidic sprays for eliminating Salmonella enterica on raw almonds. Journal of Food Science 71: 14-19.

155.Litt P, Kakani R, Jadeja R, Saha J, Kountoupis T, et al. (2020) Effectiveness of bacteriophages against biofilmforming shiga-toxigenic Escherichia coli on leafy greens and cucumbers. Mary Ann Liebert Inc.

156.Murray K, Wu F, Shi J, Xue JS, Warriner K (2017) Challenges in the microbiological food safety of fresh produce: limitations of post-harvest washing and the need for alternative interventions. Food Quality and Safety 1: 289-301.

157.Wang J, Tao D, Wang S, Li C, Li Y, et al. (2019) Disinfection of lettuce using organic acids: an ecological analysis using 16S rRNA sequencing. R.S.C. Advances 9: 1751-1752. 


\section{Pecan and Walnut Food Safety Concerns}

158. Carpenter CE, Broadbent J (2009) External concentration of organic acid anions and ph: key independent variables for studying how organic acids inhibit growth of bacteria in mildly acidic foods. Journal of Food Science 74: 12-15.

159. Beuchat LR, Mann D, Alali W (2012) Evaluation of sanitizers for inactivating Salmonella on in-shell pecans and pecan nutmeats. Journal of Food Protection 75: 19301938.

160.Kim SA, Park SH, Knueven C, Basel R, Ricke SC (2018) A decontamination approach using a combination of bisulfate of soda and peracetic acid against Listeria innocua inoculated on whole apples. Food Control 84: 106-110.

161.Fan $\mathrm{X}$, Sokorai KJB, Liao $\mathrm{CH}$, Cooke $\mathrm{P}$, Zhanget HQ (2009) Antibrowning and antimicrobial properties of sodium acid sulfate in apple slices. Journal of Food Science 74: 485-492.

162. Dittoe DK, Atchley JA, Feye KM, Lee JA, Knueven CJ, et al. (2019) The efficacy of sodium bisulfate salt (S.B.S.) alone and combined with peracetic acid (PAA.) as an antimicrobial on whole chicken drumsticks artificially inoculated with Salmonella enteritidis. Frontiers in Veterinary Science 6: 6.

163. Sheng L, Shen X, Su Y, Korany A, Knueven CJ et al. (2020) The efficacy of sodium acid sulfate on controlling Listeria monocytogenes on apples in a water system with organic matter. Food Microbiology 92: 103595.

164.McDaniel C, Teng XM, Jaroni D, Jadeja R (2021) Investigation of the antimicrobial mode of action of sodium acid sulfate and potassium acid sulfate. Food Science \& Technology 148: 111719.

Citation: McDaniel C, Jadeja R (2021) Pecan and Walnut Food Safety Concerns. Adv in Nutri and Food Sci: ANAFS-214. 